\title{
Libraries and computer centers
}

\author{
By the ACRL Task Force on Libraries and Computer Centers
}

Richard W. Boss, Chair

\section{A progress report, May 30, 1987.}

$\mathbf{I}_{\mathrm{n}}$ n the summer of 1986, the ACRL Board of Directors established a two-year ad hoc Task Force on Libraries and Computer Centers. The need for such a task force stemmed from the varied perspectives evident throughout academia on the perceived commonality of function and purpose between libraries and computer centers. The Task Force was charged by the ACRL Board "to investigate cooperative ventures between academic libraries and computing facilities and to draft guidelines for such cooperation." Current members of the Task Force are: Richard W. Boss (chair), automation consultant, Washington, D.C.; Charles R. Andrews, Hofstra University Library; Shirley Leung, University of California Library, Irvine; Kenneth Luker, University of Utah Systems Office; Peggy Seiden, Carnegie-Mellon University Library; and Michael D. Kathman, St. John's University Library.

In response to its charge from ACRL, the Task Force divided its work into three parts: to ascertain what cooperative ventures and joint administration is occurring now in academic institutions; to identify the issues which had to be addressed; and to develop guidelines for cooperation and joint administration.

In order to accomplish its first task in advance of its original meeting at the 1987 ALA Midwinter Meeting, the Task Force surveyed 100 representative academic libraries, including members of the Association of Research Libraries, smaller university libraries and college libraries. Slightly greater than $35 \%$ of those surveyed responded to a series of questions regarding the management reporting structure employed on campus with regard to both the librarian and the computer facility director; whether or not a merger of the two facilities might be under consideration; what the major issues would be if such a merger were considered; the nature of and any issues relating to existing or potential cooperative programs between the two units; and the names of institutions which are moving in the direction of a merger or cooperative venture between the library and computer facility.

Over three-quarters of the library directors at the responding institutions reported to the vice president for academic affairs (also identified as provost), while only $45 \%$ of the directors of the principal academic computer facilities reported to the same position. Almost $10 \%$ of this latter group reported to the vice president for financial affairs, while another $10 \%$ reported to the vice chancellor or vice president for administrative affairs. Where the two administrators to whom the different directors report are not the same individual, nearly $60 \%$ of the respondents report that though different, the administrators are on the same level in the institutional hierarchy. Nearly all of the libraries $(90 \%)$ report that no change in the reporting relationships at either director level is under active consideration, though some suggest that the computing facility's reporting structure might change in the future, and others report that there is interest within both parties to integrate the two units into a scholarly information office.

Among the institutions in which the library and academic computing center directors report to the same individual, $63 \%$ of the respondents report that there is a fair amount of coordination, while another $16 \%$ report their being a little coopera- 
tion. A total of $22 \%$ of the respondents report that there is only some or no cooperation.

When asked how the library would assess the prospect of merging the two facilities into a single department on campus, a resounding $86 \%$ reported that the prospect either was possible but not likely, or was highly unlikely. Only $11 \%$ reported the prospect as being highly likely. On the other hand, while $28 \%$ of the respondents suggest that the prospects for such a merger in the next decade is highly unlikely, $36 \%$ report that it is highly likely.

Among the most frequently mentioned issues stemming from consideration of such a merger were: the administration and management of human resources; the division of library and computing center responsibilities; the ability to provide efficient, quality service; funding considerations; functional differences; physical location of the two facilities; a lack of understanding on the part of the administrations of the functions of the departments, etc.

In noting existing cooperative programs, reporting institutions indicated that services such as networking, public access catalogs, consulting, instruction, etc., system maintenance and engineering, housing of equipment, etc., already are taking place between the two departments. On the other hand, a majority of the institutions (58\%) report that there are no cooperative programs between the library and other on-campus facilities. Issues similar to those raised by the possible merger of the library and computing centers were raised in consideration of what major issues would need to be discussed were cooperative programs with other campus computer facilities to be developed.

The following academic institutions were listed by the respondents as moving in the direction of mergers and/or cooperative programs between the library and a campus computing facility: Brown University; Carnegie-Mellon University; Columbia University; Dartmouth College; Notre Dame University; University of New Mexico; University of California-Berkeley; University of Minnesota; University of Michigan; and Virginia Tech University.

Members of the Task Force undertook a number of telephone interviews with the institutions identified, as well as with some referrals made by the interviewees. The interviewees reported considerable discussion on their campuses, but for the most part little major reorganization or other activity. The following reports have been submitted by members of the Task Force.

\section{Brown University}

The vice president for computing and the university librarian both report to the provost. For some time, there has been recognition of the need and importance for the library and the computer center to work closely together.

The library and the computer center are in the process of installing an online system, which eventually will be developed as a fully integrated system accommodating all technical service functions. The library system will become a part of the campus local area network. The CPU will be located in the computer center, whose staff will provide computing and maintenance support. The library recently hired two full-time staff to work on the de-

\section{$58 \%$ reported no}

\section{cooperative}

\section{library/computer center}

\section{programs.}

velopment of the acquisitions sub-system. This staff resides in and reports to the computer center. The library and the computer center recently have begun to create a formal shared funding agreement in order to codify some of the programs already put into place.

\section{Carnegie-Mellon University}

On July 1, 1986, the operations of the libraries were combined with computing and information services to form the Division of Academic Services. The division includes the libraries, central academic computing services, audiovisual services, telecommunications, and classroom support.

The Academic Services Division is led by a vice president for academic services. The head of the libraries has become associate vice president for academic services. In addition, he retains his former title, director of libraries. This change in organization was widely discussed over a period of some months, including presentations to the Faculty Senate and to the Education Affairs Committee of the Board of Trustees.

Both the libraries and computing services are experiencing rapid changes in technology and in the expectations of their academic clientele. For the libraries, this began in the 1970s with the heavy use of computing to support traditional library operations such as cataloging and information retrieval services. Today, they are seeing a second phase in which many of the materials that the libraries make available to faculty and students are created and exist solely in electronic form. The campus computer network is a fine way to deliver these services.

Over the next few years the university will be moving from a change in basic computing technology (from a time-sharing to a distributed system) to 
a period in which the emphasis will be on using the new technology for academic purposes. This interacts with the libraries in several ways. For example, the library has taken responsibility for collecting and indexing software, and for machinereadable databases. As the focus of computing shifts from an emphasis on physical storage capacities to ways of organizing, accessing, and retrieving information from enormously large information stores, the traditional orientation and expertise of the libraries will become more and more relevant to computing services.

\section{College of St. Benedict/St. John's University}

In July of 1986 academic computing was added to the responsibilities of the joint director of libraries and media. The two academic institutions share a single VAX 785, 60 public access micros and approximately 100 other micros in labs and offices. Included under academic computing is a repair facility with 2.5 FTE technicians, a teaching and software support group with 3 FTE positions and a main frame support group with 3 FTE positions.

The decision to merge the academic computing center with the library was made because the faculty wanted more service orientation in academic computing, which they believed was present in the library, and due to a desire on the part of the joint institutional administration to bring together both information resources planning and decisionmaking.

Initially the decision to merge the two operations involved only a joint directorship, but over a sixmonth period, supervision of the library public access area gradually moved from academic computing to library staff. The institution reports having achieved a smooth transition which has proven mutually desirable. Increased dialogue between the library instruction and computer instruction staffs also has developed.

Management of the institution's computer facility initially proved to be problematic under the new arrangement. For example, it was difficult for an individual trained in librarianship to supervise and evaluate a computer technical operator. The organizational structure in the area of academic computing, therefore, had to be revised. Someone with the appropriate technical knowledge had to supervise the computer system manager, a development which is being implemented.

A close relationship also exists between administrative computing and the library. Over time, some of what now falls into academic computing's responsibility may shift to administrative computing and joint planning is underway for such a change.

The faculty reportedly is pleased with the new service orientation in academic computing, and from the point of view of both management and staff, the merger reportedly has gone as smoothly as can be expected.

\section{Dartmouth College}

Dartmouth currently is considering a 15 -year plan for the entire campus, part of which includes the possibility of a closer relationship between the computer center and the library. At the present time, there are a number of overlapping areas between the two agencies, and in the future it is possible the library may undertake responsibility for some of the academic (but no administrative) computing functions now handled by the computer center. There is no plan for either a merger or takeover by either unit at this time, and any change in areas of responsibility would be undertaken gradually.

The library's two DEC computers are housed in the computer center and are dedicated solely to library use. There is some reliance upon the computer center staff for maintenance and troubleshooting. The library has as part of its own staff three full-time programmers and a director of computer systems, who also has a library degree.

Dartmouth is somewhat unusual in that computers are heavily used throughout the campus for a variety of functions. There is a campus $L A N$. The library has its own "homegrown" public access catalog and acquisition system, and in cooperation with the mathematics faculty, the library has begun placing software in its reserve room to be used by students on library terminals.

The library and the computer center also are collaborating in other areas: working on an electronic information policy for the university (e.g., the acquisitions of electronic databases); and the establishment of a microcomputer center. With regard to the latter, the library is providing assistance in software purchase decisions. At the same time, the university librarian apparently does not foresee a merger between the library and the computer center in the near future.

\section{Holy Family College}

Holy Family College is in the initial stages of bringing academic computing under the management of the library director. Since the college does not have an academic mainframe (it has an arrangement with Temple University to run large programs), the operation will be micro-based. The rationale for making the change is that "the library is the place that gathers and disseminates information and there will be easy access" with the new structure. The library is one of the largest users of micros on campus, and its staff is able in some degree to support both hardware and software.

\section{University of Cincinnati}

The director of the computer center and the university librarian both report to the university's provost and senior vice president, who reportedly has been involved actively in fostering the working relationship between the two units. 
There apparently has been a close working relationship between the two units for over four years. It started when the library was exploring its automation options. At that time, there was a staff person working in both the library and computer center. The individual worked with the library on a half-time basis developing a RFP for an automated system. The computer center has since served as a major advisor/consultant to the library in all aspects of library automation, and the library currently is planning to enlist the assistance of the computer center with regard to office automation.

The library and the computer center had drafted a general agreement on services when they first entered into cooperative efforts in developing the online public access catalog. Their relationship reportedly has proven to be quite satisfactory. Services provided to the library are charged on a use basis, and the library soon will be the second largest customer of the computer center.

The two units have regular, formal meetings. There is a bi-weekly production meeting between the library and computer center systems personnel. In addition, there are frequent informal contacts.

There reportedly has been no discussion about merging the two units; however, there is strong administrative encouragement for them to work cooperatively.

\section{University of Minnesota}

There is no active discussion regarding the merger of the library and academic computing center; however, there are ongoing discussions and efforts to enhance cooperation between the two. To that end, a joint task force has been established and appointments to that task force have been made by the two area directors.

The task force reports the following decisions regarding machine-readable data files:

- all non-private files should be accessible;

-all non-private files should be represented bibliographically in the online catalog;

- adequate technical connections from the bibliographic database through a telecommunications link to the machine-readable database should be present;

- a formal liaison between the two areas should be established.

The group also is investigating the possibility of access through the library's online system to both bibliographic information and the content of data files such as the Census Bureau data.

The following is from the Report on Integrated Online Library Systems Conference, September 23-24, 1986, by Sharon Charles.

"Effective interaction is occurring at the University of Minnesota between the library and Administrative Information Services (AIS) which is where the library's computer for the NOTIS system is housed and operated. AIS's IBM terminals throughout the university will be able to access the library's catalog.
"The library plans to offer users the ability to search external databases with these same PCs. In addition to searching the library's catalog the user would have the option of searching external databases and sending an electronic message to the library to order materials found. The staff is investigating two methods of searching external databases. One is to use a modem on the local PC:

\section{"The library is one of the largest users of micros on} campus."

the other would be to use the central computer's connection with the national IBM data communication network. Each department has a budget for searching databases such as BRS. The library anticipated encouraging faculty to search the external databases directly. A charge-back system would be set up to fund this service.

"The library is also investigating the possibility of mounting some reference databases on its central computer, identifying the various local databases on campus that might be made available to others, and, meanwhile, reorganizing 40 reference points and 18 buildings into 4 public service departments and one bibliographic database."

\section{University of New Mexico}

Initial discussion on campus with regard to a possible merger between the computing facilities and the library reportedly has ceased, and apparently the merger is not likely to occur any time soon. Over the course of the past two years, however, serious consideration was given to such a union, and the two units briefly reported to the same administrator.

The University of New Mexico recently has faced considerable transition within its academic administration. Changes in staffing have occurred throughout the campus. One such change has resulted in the dean of general libraries having been asked to serve as acting head of the computing facilities in addition to maintaining responsibility for the library.

As this new management structure evolved, the director apparently considered the possibility of developing a more permanent combined relationship between the library and computer center; however, political differences on the campus and operational differences between the two units apparently convinced the university administration to move in other directions, and early in 1987, the reporting relationships of the two units were 
changed. Most recently, both had reported to the vice president for academic affairs, although earlier the associate vice president for computer support had reported to the vice president for business. The computer center now reports to the vice president for research, while the library continues under the academic vice president. Plans for combining the two units reportedly have been dropped.

\section{"Long-term benefits in cost and simplification appear to be positive."}

\section{Vanderbilt University}

Eighteen months ago the academic computing department was added to the responsibilities of the library director. The two operations are managed independently of one another, though there is some overlap. The rationale for keeping the two separate is the desire to maintain as simple an operation as is possible.

Each school at Vanderbilt has its own dean, and the schools operate almost as if they were separate institutions. Each school contracts with both the library and academic computing for services, which essentially market their services to the various schools. The library also contracts with the computing center for the services provided. There are two seperate staffs and two distinct organizations, though they are managed by the same person.

\section{Virginia Polytechnic Institute}

VPI has no formal relationship or true cooperative venture between the library and the computing center; rather there is a structure consisting of four discrete units which report to the vice president for information systems. The units include: the library; the computer center; the learning resources center; and telephone services. Previously the director of libraries reported to the provost, though no effective lines of communication existed among the four discrete units which had reported to different administrators. At this time, under the leadership of a vice president, there is a clear understanding of the common goals and objectives of this unit. However, apparently it still is not clear with whom certain responsibilities reside.

Representatives of the four units meet weekly. There reportedly is close cooperation and more support from the administration than there had been with the previous reporting structure. There also is more technical expertise available from among the units and a greater consciousness of the library's needs. On the other hand, as the library has its own computer and systems staff, there is little involvement between the library and the computer center, except in the case of campus networking, especially with regard to remote access to the library catalog.

\section{Weber State College}

With the appointment of the present director of information services in July 1986, the computer center and the library were combined into a newly created academic division reporting directly to the academic vice president. The director serves as the chief operating officer of both the library and the only computer center on campus.

The academic vice president reportedly had been considering the unification of the two operations and had investigated the organization in other institutions, particularly Columbia University, but the move apparently crystallized only after the computing center had a series of management and budget problems. Since the merger, the new director has focused attention on the budget and staff morale. Internal cost controls and staff reductions have resulted in the elimination of seven of the twenty-five positions at the computer center. Within the next fiscal year, the library staff also must be reduced due to state-wide funding shortages. It is perceived that such reductions will be made easier because of the increased staffing options made available by the merger.

Since July the staffs of the two units have been working closely on two fronts: a committee meets once each month to review options for enhanced organization and operation; and the two staffs are adjusting to the recently installed PALS integrated library system. These areas of contact have resulted in positive discussions, enhanced mutual respect and improved morale.

One element which ostensibly has encouraged the success of the merger is the interest on campus in personal computers. Interest in making personal computers available has come from the library, academic departments, faculty and students. The new division coordinates all these interests, the success of which is viewed as critical to the long-term success of the merger.

Other interests that the library and computer center hold in common also lent support to the concept of a merger. In particular, the two units share a role in the overall information function of the institution, and therefore the opportunity for networking electronic communications already was bringing the centers closer together. In addition, the mission of each unit included support for the educational activity of the school. For these reasons the merger seemed logical and has proven practical and successful. In fact, there is some feeling that further consolidation of other areas with the nowmerged library and computer center is possible including, for example, the student tutorial functions 
currently provided by the learning center and the media support services provided by the instructional development unit.

The academic vice president reportedly is comfortable with the current structure and results, even though the merger was begun as an interim venture to solve an immediate problem. The longterm benefits in cost and simplification appear to be positive. The questions raised by the faculty have centered on how competent the library director would be to manage the computer technology, a discipline admittedly outside his previous experience. However, the incumbent's "facilitative" approach to those questions appears to have helped win support. The professors of computer courses reportedly were and remain the most wary about the consolidation, but the progress realized to date indicates that they too eventually will endorse the arrangement.

The staff at the college believes that for a merger to succeed there first must be a positive expectation of success, particularly among the staffs of the merged units. Of greater importance, however, are said to be the management and communication abilities of the individuals involved, and the willingness of the staffs to cooperate with one another.

\section{Issues Papers}

Members of the Task Force prepared a series of issues papers that provided background for the discussions at ALA Annual Conference in San Francisco. The group will attempt to complete a first draft of guidelines, with a view to completing them by January 1988.

\section{ACRL actions, June 1987}

\section{Highlights of the Annual Conference meetings of the ACRL Board of Directors.}

$\mathbf{T}$ he Board of Directors of the Association of College and Research Libraries met twice during the ALA Annual Conference in San Francisco: on June 27, 1987, and June 30, 1987.

\section{Accreditation}

While confirming its commitment to the MLS as the terminal degree for professional librarians, the Board voted to support an AASL proposal that ALA join the National Council for Accreditation of Teacher Education (NCATE) and designate AASL the responsible participant in the NCATE accreditation process as it relates to school library media education programs not eligible for accreditation by ALA.

\section{Acid-free paper}

The Board approved the following policy on the use of acid-free paper developed by the Publications Committee: "that by 1990, ACRL will begin publishing all serial publications of the Division on acid-free paper, with the exception of ephemeral publications such as but not limited to section newsletters and handbooks." The Publications Committee will review cases in which an exception is being requested to this requirement.

\section{ALA Divisions}

The Board had an opportunity to pose questions about the proposed "Policies of the American Library Association in Relation to Its Divisions" to members of ALA's Committee on Program Evaluation and Support (COPES). ACRL members Carla Stoffle, Richard Olsen, aıd Patricia Schuman represented COPES.

The Board endorsed a report to the ALA Execu- 